\title{
A Candidate Case for Lymphocytic Infundibulo-Neurohypophysitis Mimicking a Neurohypophysial Tumor
}

\author{
Satoru TsujI, Juji TaKeuchi*, Makoto KoH, Masatoshi Mizuta, \\ Yoshie Azuma, Mariko Oishi, Yoshiharu Akazawa and Hideshi Kuzuya
}

\begin{abstract}
A 56-year-old Japanese man presented with a 2-month duration of polyuria and polydipsia. The diagnosis of diabetes insipidus was confirmed by water deprivation and vasopressin injection. The secretory function of the adenohypophysis was estimated as normal by a variety of provocative tests. Magnetic resonance imaging (MRI) displayed the loss of the hyperintense signal of the neurohypophysis and a tumor-like lesion confined to the neurohypophysis. The tissue specimen resected at transsphenoidal surgery showed diffuse lymphocytic infiltration. These findings suggest that this is a candidate case for lymphocytic infundibuloneurohypophysitis (LIN) that is not identical to classical lymphocytic hypophysitis. This patient will be followed up to determine whether this case simply represents an early stage of classical hypophysitis or a different clinical entity.
\end{abstract}

(Internal Medicine 36: 293-297, 1997)

Key words: diabetes insipidus, magnetic resonance imaging (MRI), neurohypophysis, transsphenoidal surgery

\section{Introduction}

Lymphocytic infundibuloneurohypophysitis (LIN) is proposed to be a clinical entity differing from lymphocytic hypophysitis (1). Lymphocytic hypophysitis is an inflammatory lesion, probably caused by autoimmune derangement, of the pituitary gland which causes adenohypophysial insufficiency, primarily in women during late pregnancy or postpartum period. It is characterized by lymphocytic infiltration and destruction of the anterior pituitary $(1,2)$. In contrast, the LIN lesion nests specifically in the neurohypophysis, causing diabetes insipidus. In the case of LIN, T1-weighted scan of magnetic resonance imaging (MRI) displays the loss of a hyperintense signal that characterizes a normal functioning neurohypophysis $(3,4)$.

For editorial comment, see $\mathrm{p} 238$.

The secretory function of the adenohypophysis is relatively well maintained. The inflammatory process is self-limited and can regress spontaneously like lymphocytic hypophysitis
(1). It remains to be clarified whether the inflammatory lesions of LIN and classical lymphocytic hypophysitis are explained by the same pathogenetic process and just depend on the site of the lesion for the different appearance.

We describe here a candidate case for LIN in a male who was admitted because of severe polyuria and polydipsia and underwent transsphenoidal operation since MRI disclosed a small tumor confined to the neurohypophysis; eventually a diagnosis of LIN was made based upon the histopathological examination.

\section{Case Report}

The patient was a 56-year-old Japanese man. He had been free from any diseases or injuries except for lumbar herniated disk when he was 51 years old. His mother had died of rectum cancer but no other ailment was recorded in his family history, such as diabetes mellitus, thyroid disease, or rheumatoid arthritis. Two months before admission he had experienced a sudden onset of polyuria and polydipsia. He visited our clinic with the chief complaints of repeated nocturia and calf cramp attacks.

From the Division of Endocrine and Metabolic Diseases, Department of Clinical Research, Kyoto National Hospital, Kyoto and *Division of Neurosurgery, Utano Sanatorium National Hospital, Kyoto 
Table 1. Laboratory Data on Admission

\begin{tabular}{lrlr}
\hline (Urinalysis) & & Total cholesterol & $225 \mathrm{mg} / \mathrm{dl}$ \\
Protein & $(-)$ & HDL-cholesterol & $40 \mathrm{mg} / \mathrm{dl}$ \\
Glucose & $(-)$ & Triglyceride & $182 \mathrm{mg} / \mathrm{dl}$ \\
Occult blood & $(-)$ & Fasting plasma glucose & $95 \mathrm{mg} / \mathrm{dl}$ \\
Specific gravity & 1.005 & Blood urea nitrogen & $9 \mathrm{mg} / \mathrm{dl}$ \\
(Complete Blood Count) & & Creatinine & $0.9 \mathrm{mg} / \mathrm{dl}$ \\
White blood cell & $8,700 / \mathrm{mm}^{3}$ & Uric acid & $6.6 \mathrm{mg} / \mathrm{dl}$ \\
Red blood cell & $509 \times 10^{4} / \mathrm{mm}^{3}$ & Sodium & $143 \mathrm{mEq} / l$ \\
Hemoglobin & $15.2 \mathrm{~g} / \mathrm{dl}$ & Potassium & $4.3 \mathrm{mEq} / l$ \\
Hematocrit & $45.1 \%$ & Chloride & $103 \mathrm{mEq} / l$ \\
Platelets & $16.8 \times 10^{4} / \mathrm{mm}^{3}$ & Calcium & $9.3 \mathrm{mg} / \mathrm{dl}$ \\
(Blood chemistry) & & Inorganic phosphate & $3.3 \mathrm{mg} / \mathrm{dl}$ \\
Total protein & $6.3 \mathrm{~g} / \mathrm{dl}$ & (Serology) & \\
Albumin & $4.0 \mathrm{~g} / \mathrm{dl}$ & C-reactive protein & $<0.28 \mathrm{mg} / \mathrm{dl}$ \\
Total bilirubin & $0.5 \mathrm{mg} / \mathrm{dl}$ & Rheumatoid factor & $<21 \mathrm{IU} / \mathrm{ml}$ \\
Aspartate aminotransferase & $16 \mathrm{IU} / l$ & Antimicrosomal antibody & $(-)$ \\
Alanine aminotransferase & $25 \mathrm{IU} / l$ & Antithyroglobulin antibody & $(-)$ \\
Alkaline phosphatase & $179 \mathrm{IU} / l$ & Antinuclear antibody & $(-)$ \\
$\gamma$-glutamyl transferase & $26 \mathrm{IU} / l$ & Antipituitary antibody & $(-)$ \\
Lactate dehydrogenase & $410 \mathrm{IU} / l$ & HLA typing A24 A2 A24 B59 B70 CW1 \\
Choline esterase & $480 \mathrm{IU} / l$ & & CW7 DR1 DR8 DQ1 \\
\hline
\end{tabular}

His height was $174 \mathrm{~cm}$, body weight $73.5 \mathrm{~kg}$, blood pressure $118 / 70 \mathrm{mmHg}$, and pulse rate $65 / \mathrm{min}$. He showed no abnormal sign other than dry mouth and coated tongue on physical examination. Ophthalmological examination showed normal visual fields. Table 1 shows the laboratory data on admission. No particularly abnormal findings were noted. His daily urine output was up to $10 l /$ day. His urine and plasma osmolarity were 120 and $289 \mathrm{mOsm} / \mathrm{kg}$, respectively, before water deprivation. Peak urine osmolarity was $228 \mathrm{mOsm} / \mathrm{kg}$ when $1.2 \mathrm{~kg}$ body weight was lost after water deprivation. The urine osmolarity was further increased up to $345 \mathrm{mOsm} / \mathrm{kg}$ following intravenous injection of vasopressin $(0.1 \mathrm{U})$. The peak plasma antidiuretic hormone (ADH) level was $0.6 \mathrm{pg} / \mathrm{ml}$ after water deprivation. He was given a diagnosis of central diabetes insipidus.

Plasma levels of immunoreactive (IR)-growth hormone (GH), adrenocorticotropic hormone (ACTH), luteinizing hormone ( $\mathrm{LH})$, follicle stimulating hormone (FSH), prolactin (PRL), thyroid stimulating hormone (TSH) and cortisol were determined by specific radioimmunoassay (RIA) with commercially available kits (solid phase method). The challenge test of IR-GH to intravenous infusion of $100 \mu \mathrm{g}$ of somatolerin acetate (GRH; Sumitomo Pharm. Co., Osaka) showed a blunted IR-GH response, but the secretory capacity of the adenohypophysis was interpreted as almost normal by the results of other provocative tests (Tables 2,3).

Serum anti-pituitary antibodies were measured using the rat pituitary (5), which turned out to be negative (Table 1). The antinuclear antibody and rheumatoid factor, and antithyroglobulin and antithyroid microsomal antibodies were all negative. HLA typing of the patient showed a phenotype of A2 A24 B59 B70 CW1 CW7 DR1 DR8 DQ1.

MRI revealed a round tumor-like lesion of about $5 \mathrm{~mm}$ in
Table 2. Results of Provocative Tests of the Adenohypophysial Hormones before and after Transsphenoidal Surgery (Part 1)

Responses to gonadotropin releasing hormone (100 $\mu \mathrm{g}$, i.v.)

\begin{tabular}{lcccccc}
\hline & before & $15 \mathrm{~min}$ & $30 \mathrm{~min}$ & $60 \mathrm{~min}$ & $90 \mathrm{~min}$ & $120 \mathrm{~min}$ \\
\hline LH before & 3.0 & 9.6 & 13.0 & 14.6 & 13.0 & 12.1 \\
LH after & 2.5 & 7.5 & 10.4 & 11.7 & 11.7 & 10.9 \\
& & & & & & \\
FSH before & 17.1 & 24.3 & 27.8 & 31.2 & 32.8 & 34.4 \\
FSH after & 17.1 & 19.7 & 22.7 & 25.7 & 26.0 & 26.5 \\
\hline
\end{tabular}

LH (luteinizing hormone) and FSH (follicle stimulating hormone) before or after surgery in $\mathrm{mIU} / \mathrm{ml}$.

Responses to TRH ( $500 \mu \mathrm{g}$, i.v.)

0 $\quad 15 \mathrm{~min} 30 \mathrm{~min} 45 \mathrm{~min} 60 \mathrm{~min} 90 \mathrm{~min} 120 \mathrm{~min}$

\begin{tabular}{lrrrrrrr}
\hline PRL before & 8.2 & 26.9 & 27.8 & 25.3 & 22.6 & 17.6 & 13.6 \\
PRL after & 4.7 & 16.4 & 18.2 & 16.6 & 13.5 & 10.2 & 8.8 \\
& & & & & & & \\
TSH before & 1.42 & 6.09 & 8.47 & 7.07 & 5.81 & 5.03 & 4.06 \\
TSH after & 0.93 & 3.66 & 5.77 & 5.55 & 5.39 & 5.82 & 3.48 \\
\hline
\end{tabular}

PRL (prolactin) in $\mathrm{ng} / \mathrm{ml}$ and TSH (thyroid stimulating hormone) in $\mu \mathrm{U} / \mathrm{ml}$ before or after surgery.

TRH: thyrotropin releasing hormone. 
Lymphocytic Infundibulo-Neurohypophysitis

Table 3. Results of Provocative Tests of the Adenohypophysial Hormones before and after Transsphenoidal Surgery (Part 2)

Responses to growth hormone releasing hormone (100 $\mu$ g, i.v.)

\begin{tabular}{lllllll}
\hline & 0 & $15 \mathrm{~min}$ & $30 \mathrm{~min}$ & $60 \mathrm{~min}$ & $90 \mathrm{~min}$ & $120 \mathrm{~min}$ \\
\hline GH before & 0.07 & 1.9 & 1.7 & 1.6 & 3.2 & 2.0 \\
GH after & 0.54 & 1.2 & 1.0 & 1.2 & 1.3 & 2.6 \\
\hline
\end{tabular}

$\mathrm{GH}$ (growth hormone) in $\mathrm{ng} / \mathrm{ml}$ before or after surgery.

Responses to insulin-induced hypoglycemia $(0.1 \mathrm{U} / \mathrm{kg}$, i.v. $)$

\begin{tabular}{|c|c|c|c|c|c|c|c|}
\hline & 0 & $15 \mathrm{~min}$ & $30 \mathrm{~min}$ & $45 \mathrm{~min}$ & $60 \mathrm{~min}$ & $90 \mathrm{~min}$ & $120 \mathrm{~min}$ \\
\hline PG before & 107 & 56 & 33 & 49 & 81 & 99 & 101 \\
\hline PG after & 94 & 57 & 32 & 44 & 63 & 81 & 89 \\
\hline GH before & 0.19 & 0.27 & 1.1 & 10 & 19 & 13 & 8.9 \\
\hline GH after & 0.16 & 0.11 & 0.16 & 12 & 19 & 17 & 15 \\
\hline PRL before & 8.1 & 8.0 & 8.1 & 8.8 & 16.6 & 12.9 & 11.5 \\
\hline PRL after & 5.4 & 5.6 & 5.9 & 12.9 & 21.5 & 19.6 & 14.7 \\
\hline ACTH before & 43 & 33 & 35 & 340 & 300 & 96 & 49 \\
\hline ACTH after & 71 & 28 & 44 & 740 & 610 & 130 & 180 \\
\hline F before & 12.6 & 11.5 & 10.8 & 16.7 & 21.1 & 19.5 & 14.9 \\
\hline F after & 5.5 & 5.5 & 6.0 & 13.1 & 14.5 & 15.4 & 18.3 \\
\hline
\end{tabular}

PG (plasma glucose) in mg/dl, GH (growth hormone) in ng/ml, PRL (prolactin) in $\mathrm{ng} / \mathrm{ml}, \mathrm{ACTH}$ (adrenocorticotropic hormone) in $\mathrm{pg} / \mathrm{ml}$ and $\mathrm{F}$ (cortisol) in $\mu \mathrm{g} / \mathrm{dl}$ before or after surgery.
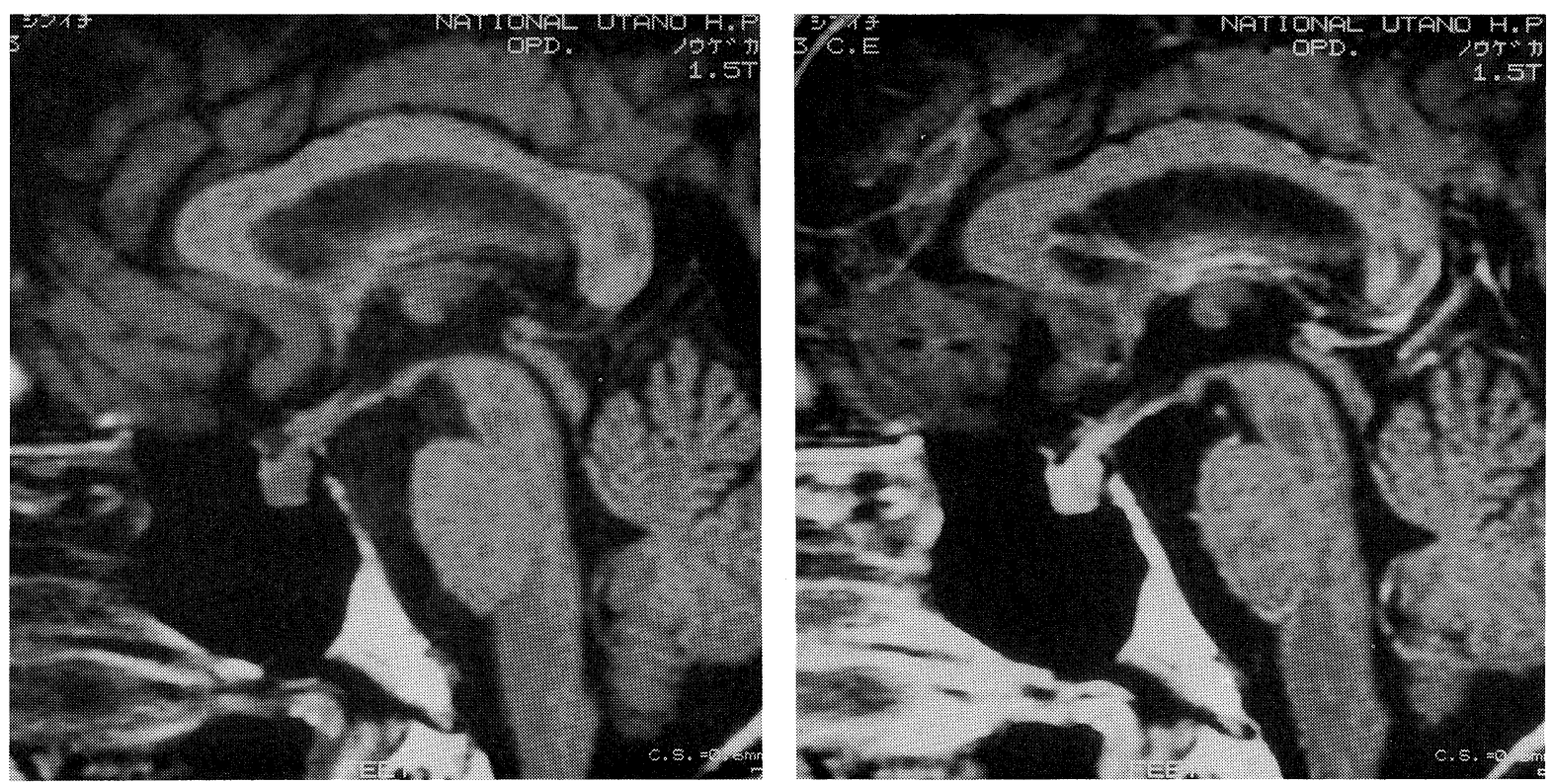

Figure 1. Saggital T1-weighted MRI scans before (left panel) and after (right panel) gadolinium enhancement. The hyperintense signal is absent in the neurohypophysis in the left panel. The intensity of the neurohypophysis is enhanced by gadolinium in the right panel, leaving a round non-intensified lesion. 

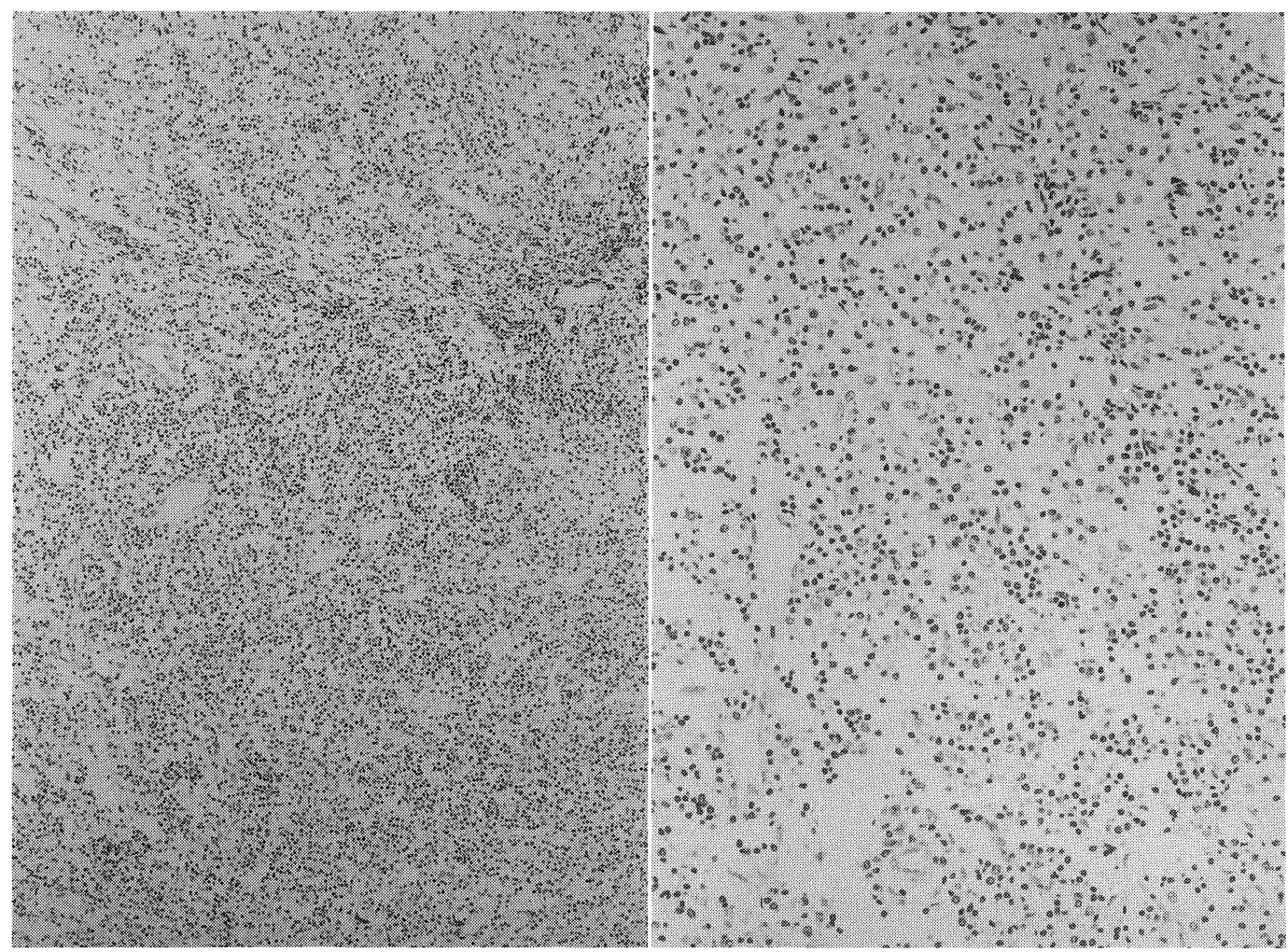

Figure 2. Light microscopic appearance of hematoxylin-eosin stain of the pituitary tissue specimen with lower magnification $(\times 25$, left $)$ and higher magnification $(\times 100$, right $)$. The inflammatory infiltrate consists of mature lymphocytes and some plasma cells, accompanied by vascular hyperplasia.

diameter confined to the neurohypophysis which lacked the hyperintense signal on T1-weighted image (Fig. 1). The tumorappearing lesion was not enhanced with gadolinium, a contrast agent. Because the patient was suspected to have a tumor in the neurohypophysis, transsphenoidal surgery was performed. The mass lesion of the neurohypophysis was very soft and easily removed but macroscopically the border was not so distinct from the surrounding normal hypophysis. The histological examination of the resected specimen revealed diffuse infiltration of mainly mature lymphocytes and some plasma cells without any evidence of glioma, sarcoidosis, tuberculosis, histiocytosis X, plasmacytoma or giant cell granuloma (Fig. 2). No specific immunocytochemical staining was done.

Provocative tests were repeated 1 month after transsphenoidal surgery. There was no significant change in the responsiveness of anterior pituitary hormones to a variety of secretagogues between before and after surgery (Tables 2,3). Plasma IRACTH showed very high responses to insulin-induced hypoglycemia before and after surgery. No replacement therapy was necessary for the anterior pituitary hormones. The patient was given intranasal desmopressin acetate $(10 \mu \mathrm{g} /$ day $)$ and his urine volume was reduced to 2 to $3 l /$ day.

\section{Discussion}

Lymphocytic hypophysitis usually occurs in women and clinically is associated with headaches, visual symptoms and signs of hypopituitarism $(2,6,7)$. Such patients have unequivocal evidence of anterior pituitary hypofunction and many present with amenorrhea, fatigue or weakness, and their symptoms are often associated with pregnancy. The radiological appearance is characterized by a sellar mass lesion with or without suprasellar extension $(2,6,7)$. This is why lymphocytic hypophysitis is often mistaken for a pituitary tumor. A tumor is, however, not found at surgery, and the histopathological examination of the pituitary shows chronic inflammation, with lymphocytic infiltration and plasma cells confined to the adenohypophysis $(2,6$, 7). Diabetes insipidus rarely has been described as part of the clinical presentation of lymphocytic hypophysitis and was notably absent in 30 cases in a recent review (2). There are case reports which discuss lymphocytic hypophysitis featuring permanent diabetes insipidus $(1,6-10)$. The fact that one has diabetes insipidus suggests extension of the disease process into the median eminence and hypothalamus in addition to the involvement of the neurohypophysis $(11,12)$, which is not identical to the classical features of lymphocytic hypophysitis that is thought to be confined to the anterior pituitary. In the case presented here, the neurohypophysis and hypothalamus are assumed to be involved, as evidenced by the permanent diabetes insipidus. In fact, an infundibulo-neurohypophysitis causing diabetes insipidus, with involvement of the infundibulm, infundibular stalk and neural lobe, sparing the anterior lobe of 
the pituitary, has been reported (8). LIN has been proposed as a different clinical entity from classical lymphocytic hypophysitis and as a cause of idiopathic diabetes insipidus (1). There have been a few male cases of lymphocytic hypophysitis reported. Ahmed et al (6) reported two male cases of necrotizing infundibulo-hypophysitis, as a unique clinical syndrome, characterized by diabetes insipidus and hypopituitarism; i.e., involvement of the adenohypophysis, neurohypophysis, and hypothalamus. Their cases are in contrast to the case reported here, in that the present case showed only the dysfunction of the hypothalamo-neurohypophysial system causing diabetes insipidus without any sign of adenohypophysial hypofunction and there was no necrosis found in the histological specimen. There might very likely be some cases of lymphocytic panhypophysitis that are composed of lymphocytic adenohypophysitis and LIN together $(9,10)$, showing diabetes insipidus and hypopituitarism.

The etiology of the inflammatory process in the present case is not clear as in previous reports. The histological characteristics typical of a granulomatous lesion was not found in the resected specimen. Although there was no evidence of organspecific autoimmunity, an autoimmune etiology cannot be excluded. Specific immunohistochemical stainings were not performed on the specimen that was taken from the neural lobe at surgery. The inflammatory process was assumed to spare the adenohypophysis because the secretory capacity of the adenohypophysis was almost normal before and after operation and the specimen did not include anterior pituitary glandular cells. Further, the pre-operation MRI showed confinement of the mass lesion to the neural lobe; these findings disappeared on post-operation MRI with no change in the anterior lobe. The scan image of MRI was compatible with the diagnosis of idiopathic diabetes insipidus (1), in that the adenohypophysis and hypothalamus appeared normal and the hyperintense signal of the neurohypophysis was absent. The enlargement of the neurohypophysis and thickening of the pituitary stalk are reportedly accompanied by the enhancement of its intensity by gadolinium (1). These abnormal findings on MRI were not definite in this patient. The different feature was the lack of enhancement by gadolinium where the pathological lesion was thought to exist, which plausibly suggested pituitary tumor like glioma. In this setting, transsphenoidal surgery may be needed to distinguish pituitary inflammation from pituitary tumor though it may eventually come to be a biopsy, because there are no definitive and specific MRI findings for hypophysitis (13). There is no clear answer for the absence of enhancement with gadolinium found in this case.

The IR-GH response to growth hormone-releasing hormone was low but the IR-GH response to insulin-induced hypoglycemia was normal. There might be some derangements in the regulation of growth hormone secretion in patients with LIN either in their hypothalamus or median eminence (1). The IR-ACTH response to hypoglycemia was exceedingly high, especially after surgery, for which the precise reason remains to be clarified. Most cases of lymphocytic adenohypophysitis reportedly show adrenal insufficiency secondary to reduced ACTH secretion. Certain cytokines, however, secreted from the inflammatory locus in the posterior pituitary like LIN could be related to the hyper-responsiveness of corticotropes in the anterior pituitary to hypoglycemia and/or hyper-secretion of corticotropin releasing factor $(14,15)$.

In summary, the patient presented here is not a typical case of classical lymphocytic hypophysitis; first point, this case was a male. Secondly, the pathological lesion was located in the neurohypophysis, acting a tumor and causing diabetes insipidus without adenohypophysial hypofunction or symptoms and signs of a mass lesion. These findings may imply that this is a candidate case for LIN. This patient will be followed up to determine whether this case represents the early stage or a variant of classical lymphocytic hypophysitis, or stands for a different clinical entity.

\section{References}

1) Imura $\mathrm{H}$, Nakao $\mathrm{K}$, Shimatsu $\mathrm{A}$, et al. Lymphocytic infundibuloneurohypophysitis as a cause of central diabetes insipidus. N Engl J Med 329: 683, 1993.

2) Cosman F, Post KD, Holub DA, Wardlaw SL. Lymphocytic hypophysitis. Report of 3 new cases and review of the literature. Medicine (Baltimore) 68: $240,1989$.

3) Fujisawa I, Nishimura K, Asato R, et al. Posterior lobe of the pituitary in diabetes insipidus: MR findings. J Comput Assist Tomogr 11: 221, 1987.

4) Gudinchet F, Brunelle F, Barth MO, et al. MR imaging of the posterior hypophysis in children. AJR Am J Roentgenol 153: 351, 1989.

5) Sugiura M, Hashimoto A, Shizawa M, et al. Heterogeneity of anterior pituitary cell antibodies detected in insulin-dependent diabetes mellitus and adrenocorticotropic hormone deficiency. Diabetes Res 3: 111, 1986.

6) Ahmed SR, Aiello DP, Page R, Hopper K, Towfighi J, Santen RJ. Necrotizing infundibulo-hypophysitis: A unique syndrome of diabetes insipidus and hypopituitarism. J Clin Endocrinol Metab 76: 1499, 1993.

7) Thodou E, Asa SL, Kontogeorgos G, Kovacs K, Horvath E, Ezzat S. Clinical case seminar: Lymphocytic hypophysitis: Clinicopathological findings. J Clin Endocrinol Metab 80: 2302, 1995.

8) Kojima H, Nojima T, Nagashima K, Ono Y, Kudo M, Ishikura M. Diabetes insipidus caused by lymphocytic infundibuloneurohypophysitis. Arch of Pathol Lab Med 113: 1399, 1989.

9) Nussbaum CE, Okawara SH, Jacobs LS. Lymphocytic hypophysitis with involvement of the cavernous sinus and hypothalamus. Neurosurgery 28 : 440, 1991.

10) Koshiyama H, Sato H, Yorita S, et al. Lymphocytic hypophysitis presenting with diabetes insipidus: case report and literature review. Endocr J 41: 93, 1994.

11) Heinbecker P, White HL. Hypothalamo-hypophysial system and its relation to water balance in the dog. Am J Phy 133: 582, 1941.

12) Kovacs K, Horvath E. Morphology of the pituitary in health and disease. in: Principles and practice of endocrinology and metabolism, Becker KL, Ed. J.B. Lippincott Company, Philadelphia, 1990, p. 109.

13) Ahmadi J, Meyers GS, Segall HD, Sharma OP, Hinton DR. Lymphocytic adenohypophysitis: contrast-enhanced MR imaging in five cases. Radiology 195: 30, 1995.

14) Sapolsky R, Rivier C, Yamamoto G, Plotsky P, Vale W. Interleukin-1 stimulates the secretion of hypothalamic corticotropin-releasing factor. Science 238: 522, 1987.

15) Zhou D, Shanks N, Riechman SE, Liang R, Kusnecov AW, Rabin BS. Interleukin 6 modulates interleukin-1- and stress-induced activation of the hypothalamic-pituitary-adrenal axis in male rats. Neuroendocrinology 63: 227, 1996. 